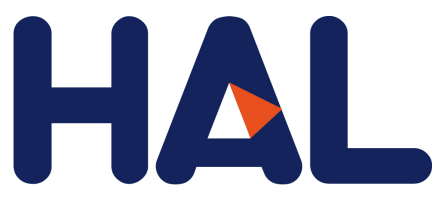

archives-ouvertes

\title{
Vacuum ultraviolet-absorption spectroscopy and delocalized plasma-induced emission used for the species detection in a down-stream soft-etch plasma reactor Robert Soriano, Gilles Cunge
}

\section{To cite this version:}

Robert Soriano, Gilles Cunge. Vacuum ultraviolet-absorption spectroscopy and delocalized plasmainduced emission used for the species detection in a down-stream soft-etch plasma reactor. Journal of Vacuum Science and Technology A, American Vacuum Society, 2020, 38 (4), pp.043002. 10.1116/6.0000134 . hal-02935381

\section{HAL Id: hal-02935381 \\ https://hal.archives-ouvertes.fr/hal-02935381}

Submitted on 7 Dec 2020

HAL is a multi-disciplinary open access archive for the deposit and dissemination of scientific research documents, whether they are published or not. The documents may come from teaching and research institutions in France or abroad, or from public or private research centers.
L'archive ouverte pluridisciplinaire HAL, est destinée au dépôt et à la diffusion de documents scientifiques de niveau recherche, publiés ou non, émanant des établissements d'enseignement et de recherche français ou étrangers, des laboratoires publics ou privés. 


\section{Vacuum ultraviolet-absorption spectroscopy and delocalized plasma-induced emission used for the species detection in a down- stream soft-etch plasma reactor}

Cite as: J. Vac. Sci. Technol. A 38, 043002 (2020); https://doi.org/10.1116/6.0000134

Submitted: 21 February 2020 . Accepted: 13 May 2020 . Published Online: 04 June 2020

Robert Soriano, Gilles Cunge, and Nader Sadeghi

COLLECTIONS

Paper published as part of the special topic on Special Topic Collection Commemorating the Career of John Coburn Note: This paper is part of the Special Topic Collection Commemorating the Career of John Coburn.
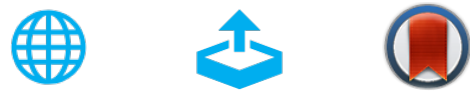

\section{ARTICLES YOU MAY BE INTERESTED IN}

Isotropic dry etching of Si selectively to $\mathrm{Si}_{0.7} \mathrm{Ge}_{0.3}$ for $\mathrm{CMOS}$ sub-10 $\mathrm{nm}$ applications

Journal of Vacuum Science \& Technology A 38, 033002 (2020); https://

doi.org/10.1116/1.5143118

Inside the mysterious world of plasma: A process engineer's perspective

Journal of Vacuum Science \& Technology A 38, 031004 (2020); https://

doi.org/10.1116/1.5141863

Gas-phase diagnostic studies of $\mathrm{H}_{2}$ and $\mathrm{CH}_{4}$ inductively coupled plasmas Journal of Vacuum Science \& Technology A 38, 033010 (2020); https://

doi.org/10.1116/6.0000090

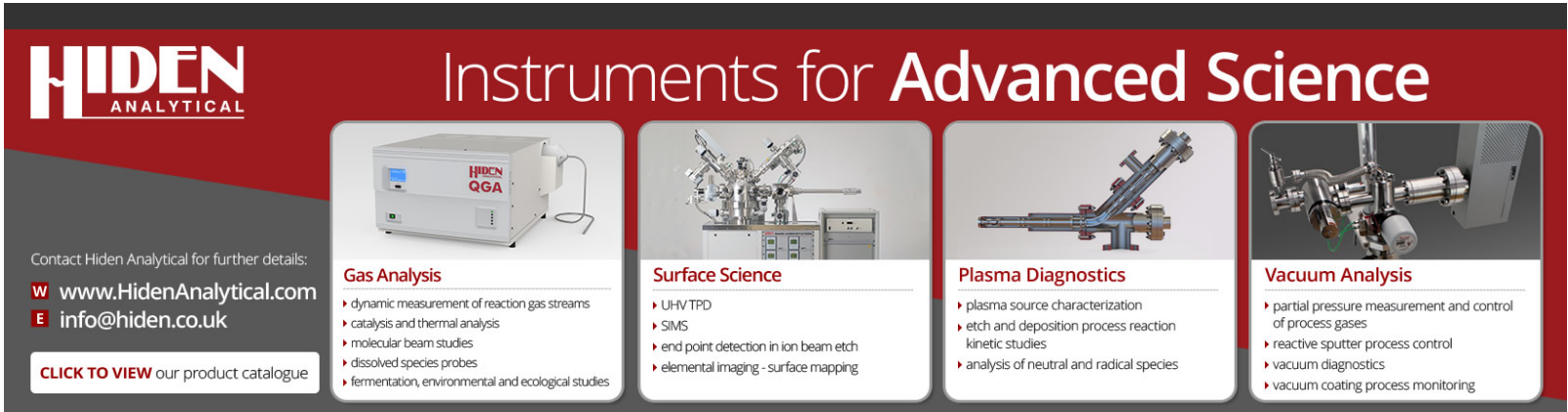




\title{
Vacuum ultraviolet-absorption spectroscopy and delocalized plasma-induced emission used for the species detection in a down-stream soft-etch plasma reactor
}

Cite as: J. Vac. Sci. Technol. A 38, 043002 (2020); doi: $10.1116 / 6.0000134$

Submitted: 21 February 2020 . Accepted: 13 May 2020 .

Published Online: 4 June 2020

Robert Soriano, Gilles Cunge, ${ }^{\text {) }}$ and Nader Sadeghi

\author{
AFFILIATIONS \\ Laboratoire des Technologies de la Microélectronique, Univ. Grenoble-Alpes, CNRS, CEA/LETI Minatech, Grenoble, France
}

Note: This paper is part of the Special Topic Collection Commemorating the Career of John Coburn.

a)Electronic mail: gilles.cunge@cea.fr

\begin{abstract}
Vacuum ultraviolet-absorption spectroscopy (AS) and emission spectroscopy (ES) from delocalized probe plasma are implemented in the downstream chamber of a soft-etch industrial plasma reactor. A capacitively coupled plasma plasma, running in the upper compartment in $\mathrm{He} / \mathrm{NF}_{3} / \mathrm{NH}_{3} / \mathrm{H}_{2}$ mixtures at about 1 Torr, produces reactive species which flow through a shower head into a downstream chamber, where they can etch different $\mu$-electronic materials: $\mathrm{Si}, \mathrm{SiO}_{2}, \mathrm{SiN}$, etc. The $\mathrm{ES}$ reveals the presence of $\mathrm{F}$ atoms, while the dissociation rates of $\mathrm{NF}_{3}$ and $\mathrm{NH}_{3}$ are deduced from the AS, as well as the density of $\mathrm{HF}$ molecules, produced by chemical chain-reactions between dissociation products of $\mathrm{NF}_{3}, \mathrm{NH}_{3}$, and $\mathrm{H}_{2}$. The variations of $\mathrm{HF}$ density as a function of the $\mathrm{NH}_{3}$ flow rate suggest the possible formation of $\mathrm{NH}_{4} \mathrm{~F}$ molecules in the plasma.
\end{abstract}

Published under license by AVS. https://doi.org/10.1116/6.0000134

\section{INTRODUCTION}

Downstream etchers known as remote plasma sources (RPS) were introduced in the early 1970s for resist stripping applications. ${ }^{1,2}$ However, until recently, they have drawn relatively little scientific interest compared to other plasma sources because they inevitably lead to isotropic etching, which restrict their use to specific applications. But as the size and thickness of transistors continue to shrink, new processes are required to etch high aspect ratio (AR) nanofeatures. For example, ultrahigh selective isotropic etching in RPS is needed for specific steps involved in the patterning of FinFet ${ }^{3}$ transistors and $3 \mathrm{D}$ Nand memories. ${ }^{4}$ RPS processes have also started to be investigated ${ }^{5}$ to replace wet processes that show severe limitation to remove materials in AR structures due to capillary forces. Finally, plasma induced damage (mostly caused by energetic ions and photons) has become a major concern and new etching technologies (involving RPS in combination with typical plasmas) such as the Smart Etch ${ }^{6}$ and other ALE processes ${ }^{7}$ have been introduced to etch materials anisotropically without damages.
As a matter of fact, the interest of RPS lies in their capabilities to produce purely chemical etching with radicals leading to high selectivity and absence of structural damages in underlayers.

In many of the above mentioned applications, the goal is to etch selectively an $\mathrm{Si}$ alloy, respectively, to another $\mathrm{Si}$ alloy (e.g., $\mathrm{Si}$, $\mathrm{SiN}$, and $\mathrm{SiO}_{2}$ ), which can be achieved in F-based RPS plasmas. $\mathrm{NF}_{3}$ is typically used as an $\mathrm{F}$ source due to its high cross section for dissociative electron attachment. ${ }^{8}$ Furthermore, $\mathrm{F}$ atom's density in the discharge can be controlled by adding $\mathrm{H}$ or $\mathrm{O}$ containing gases into $\mathrm{NF}_{3}$. For example, downstream plasmas in $\mathrm{NF}_{3} / \mathrm{O}_{2}$ mixtures have been used to etch selectively $\mathrm{SiN}$ to $\mathrm{SiO}_{2},{ }^{9}$ and remarkable performances were obtained recently ${ }^{4}$ to remove $\mathrm{SiN}$ from trenches with AR of 100, thus performing better than in wet processes.

On the other hand, $\mathrm{H}$ addition to $\mathrm{NF}_{3}$ in RPS (which are studied in this paper) leads to new etching possibilities. Initially, such processes were introduced ${ }^{10}$ to deoxidize silicon surfaces, i.e., etch $\mathrm{SiO}_{2}$ selectively to $\mathrm{Si}$ prior to epitaxy, or to clean shallow trench isolation (STI) trenches. These processes were achieved in 
$\mathrm{NF}_{3} / \mathrm{H}_{2}$ (Refs. 11 and 12 ) or $\mathrm{NF}_{3} / \mathrm{NH}_{3}$ chemistry. ${ }^{13}$ The addition of hydrogen to $\mathrm{NF}_{3}$ does not only serves to reduce $\mathrm{F}$ atoms density but also to promote the formation of new radicals such as HF or $\mathrm{NH}_{4} \mathrm{~F}$, which are believed to be the precursor to the formation of ammonium salts $\left(\mathrm{NH}_{4}\right)_{2} \mathrm{SiF}_{6}$ selectively on $\mathrm{SiON}$ and $\mathrm{SiOx}$ surfaces. ${ }^{14-16}$ In this case, there is no direct etching of the surface during the RPS step: the salt forms selectively with a material to be etched and must then be sublimated to readily etch the material. Several innovative etching processes have been developed recently based on this phenomenon, including the so-called Smart Etch process 6 and several atomic layer Etching processes ${ }^{7,17}$ all of which are two step processes: the material is first modified anisotropically on a well-controlled depth by a given plasma and the modified layer is then etched selectively in a second step, typically by an RPS in $\mathrm{NF}_{3} / \mathrm{NH}_{3}$ chemistry. The "Smart Etch" process is using energetic $\mathrm{H}_{2}$ or $\mathrm{He}$ ions generated in a capacitively coupled plasma (CCP) plasma for the first step, thus modifying several $\mathrm{nm}$ of the SiN material by ion implantation (the use of light ions prevents $\mathrm{SiN}$ sputtering), ${ }^{18,19}$ Initially, the modified $\mathrm{SiN}^{\star}$ layer was removed selectively to pristine $\mathrm{SiN}$ by a wet $\mathrm{HF}^{6}$ or by gaseous $\mathrm{HF}^{20}$ But this does not allow cycling the two step of the process with a good throughput. By contrast, by removing the modified $\mathrm{SiN}^{\star}$ layer with an RPS in $\mathrm{NF}_{3} / \mathrm{NH}_{3}$ mixtures, ${ }^{21}$ it becomes possible to perform the implantation and RPS steps without air exposure in the same specifically design chamber. ${ }^{22}$ For industrial applications, the salt formed during the RPS step is sublimated either by heating, ${ }^{17}$ or simply by reducing the pressure before the next implantation step. ${ }^{22}$ Recent work $^{22}$ has demonstrated that $\left(\mathrm{NH}_{4}\right)_{2} \mathrm{SiF}_{6}$ salt formation is efficient only on oxidized surfaces, explaining the $\mathrm{SiO}_{2} / \mathrm{Si}$ and $\mathrm{SiO}_{x} / \mathrm{SiN}$ etching selectivity as well as the $\mathrm{SiN}^{\star} / \mathrm{SiN}$ selectivity in the Smart Etch process: in the $\mathrm{H}_{2}$ or He plasma used to modify the SiN there is a considerable amount of $\mathrm{O}$ implantation in the $\mathrm{SiN}^{\star}$ originating from plasma impurities. Interestingly, while the salt formation has been widely analyzed through surface diagnostics, the origin of radicals that are precursors to their formation remains highly speculative; since the gas phase of $\mathrm{NH}_{3} / \mathrm{NF}_{3}$ RPS has never been analyzed. The consensual ${ }^{10,15,21-24}$ mechanism for the salt formation in this chemistry is described by the following stochiometric balance (real reactions at the wafer being probably the result of a long series of individual mechanistic steps),

$$
\mathrm{SiO}_{2}+2 \mathrm{NH}_{4} \mathrm{~F}+4 \mathrm{HF} \rightarrow\left(\mathrm{NH}_{4}\right)^{2} \mathrm{SiF}_{6}+2 \mathrm{H}_{2} \mathrm{O}
$$

Therefore, $\mathrm{NH}_{4} \mathrm{~F}, \mathrm{HF}$, and $\mathrm{NH}_{4} \mathrm{~F}(\mathrm{HF})$ are typically assumed to be formed in the plasma and hence they react with the surface. As a matter of fact, the work from Ogawa ${ }^{15}$ indirectly suggests that $\mathrm{NH}_{4} \mathrm{~F}$ could be produced from the reaction of $\mathrm{NH}_{3}$ gas with some fragment of $\mathrm{NF}_{3}$ (formed by heating $\mathrm{NF}_{3}$ ). The formation of $\mathrm{HF}$ in the plasma can also be expected to play a significant role in the overall chemistry and we can expect HF to be formed by the chain reactions $(2-4)$ (well known in HF laser physics): ${ }^{25-30}$

$$
\begin{gathered}
\mathrm{H}_{2}+\mathrm{F} \rightarrow \mathrm{HF}+\mathrm{H}, \\
\mathrm{H}+\mathrm{NF}_{\mathrm{X}}(\mathrm{x}=1,2) \rightarrow \mathrm{HF}+\mathrm{NF}_{\mathrm{x}-1},
\end{gathered}
$$

$$
\mathrm{NH}_{3}+\mathrm{F} \rightarrow \mathrm{NH}_{2}+\mathrm{HF} \text {. }
$$

In the present paper, we apply the vacuum ultraviolet broadband absorption spectroscopy (VUV-BBAS) in the 120-200 nm range $^{31,32}$ with a deuterium lamp as the light source for the real time monitoring of etching agents and etch products in the downstream of $\mathrm{NF}_{3}-\mathrm{NH}_{3}-\mathrm{H}_{2}$ containing plasmas of an AMAT RPS reactor especially designed to perform Smart Etching and described in detail in Ref. 22. Besides VUV-BBAS, we also have implemented a probe pulsed DC discharge to follow, by actinometry, the density of $\mathrm{F}$ atoms in the downstream chamber. By directly measuring the densities of $\mathrm{NH}_{3}, \mathrm{NF}_{3}$, and $\mathrm{HF}$, as well as the variation of $\mathrm{F}$ density as a function of the operating condition, we could get insights into the complex chemistry of these RPS plasmas.

\section{EXPERIMENT}

\section{A. Plasma reactor}

The experiments are carried out in an industrial $50 \mathrm{~cm}$ diameter remote plasma reactor (frontiers from Applied Materials) used for the soft etching of $30 \mathrm{~cm}$ diameter wafers. It is composed of two chambers separated by an about $50 \mathrm{~mm}$ thick shower head. As shown in Fig. 1, the gas, whose main component is helium and contains a few percent of $\mathrm{H}_{2}, \mathrm{NF}_{3}$, and $\mathrm{NH}_{3}$, enters the top compartment, flows through the shower head to expand into the downstream compartment and is then pumped out with a $200 \mathrm{l} / \mathrm{s}$ dry primary pump. The total gas flow rate is about 2000 SCCM and the gas pressure in the downstream chamber (DSC), measured with a capacitance gauge, is maintained to 1 Torr with a throttle valve located on the pumping pipe. A capacitively coupled plasma (CCP) is generated in the top compartment with up to $500 \mathrm{~W}$ power of 13.56 MHz radiofrequency discharge. Radicals and atoms produced by the discharge are transported by the gas flow into the DSC but the plasma production zone is limited by the shower head, blocking the extension of the discharge into the downstream compartment. Thus, only radicals are responsible for the soft etching of the wafer

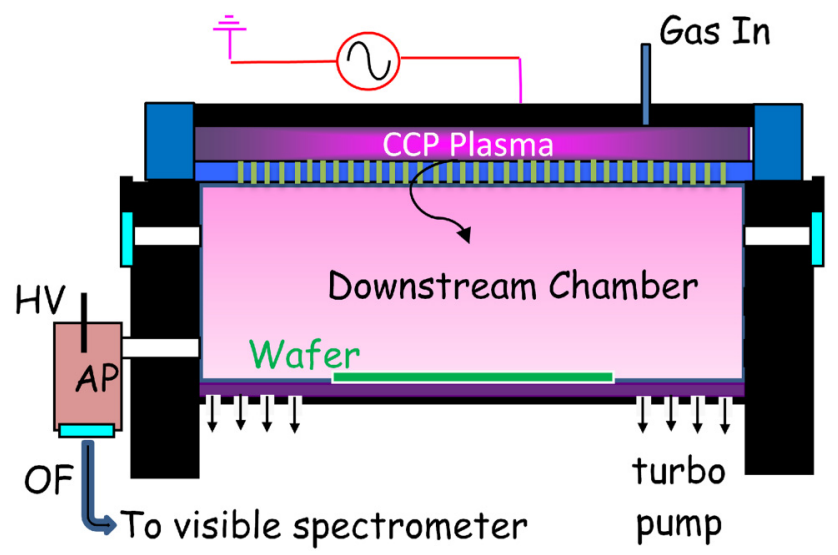

FIG. 1. Schematic of the experimental setup showing the downstream chamber with the small deported plasma (used for OES). 
positioned in the DSC, without any assistance by ion bombardment, as is the case in usual reactive ion etching processes. ${ }^{33}$ Due to the absence of viewports in the CCP zone of the reactor, no diagnostic technique can be implemented to characterize the $C C P$ plasma. However, atoms and molecules produced by the dissociation of injected molecules in this plasma and transported to the DSC have been monitored in this chamber by the vacuum ultraviolet broad-band absorption spectroscopy (VUV-BBAS) and by optical emission spectroscopy (OES). But, as a consequence of the absence of energetic electrons in the downstream plasma, no optical radiation is emitted from this region. Thus, to monitor the density of $\mathrm{F}$ atoms present in the downstream chamber, a small tube (about $4 \mathrm{~cm}$ inner diameter, $10 \mathrm{~cm}$ long) is connected to the DSC through a $4 \mathrm{~cm}$ diameter hole on the reactors' wall and an auxiliary plasma (AP) is generated inside this tube by applying a positive high voltage (HV) to an isolated, $0.2 \mathrm{~cm}$ diameter, $3 \mathrm{~cm}$ long copper road which penetrates into the tube by one of its end, as shown in Fig. 1. The opposite end of the tube is sealed by a quartz window for the OES and the inner walls of the tube act as a cathode for the auxiliary discharge.

\section{B. Actinometry with auxiliary plasma}

To follow the variation of $\mathrm{F}$ atoms densities produced by the $C C P$ discharge, the optical emission of the auxiliary discharge is collected by an optical fiber, whose other end is set on the entrance slit of a $50 \mathrm{~cm}$ focal length monochromator (Acton $500 \mathrm{i}$ ), equipped with a 600 groves $/ \mathrm{mm}$ grating and backed by a 1024 elements, $25 \mu \mathrm{m}$ pitch photodiode array. A $112 \mathrm{k} \Omega$ resistor, placed in series with the $H V$ supplier, limits the peak discharge current of the AP to about $8 \mathrm{~mA}$ with a $1 \mathrm{kV}$ applied voltage. And moreover, the $\mathrm{HV}$ is modulated at $120 \mathrm{~Hz}$, with a $5 \%$ duty cycle to keep as low as possible the dissociation of the gas inside the auxiliary discharge tube. Thus, we assume that the recorded emission intensities from the excited states of $\mathrm{F}$ and $\mathrm{He}$ atoms, at 703.7 and $706.5 \mathrm{~nm}$ lines, respectively, are proportional to the densities of these atoms in the downstream chamber. The actinometry method, ${ }^{34,35}$ with $706.5 \mathrm{~nm}$ helium line for the reference intensity, is used to follow changes on $\mathrm{F}$ atoms' densities when varying the amount of the added gases to helium. We are aware that the large difference between the excitation energies of helium line $(22.7 \mathrm{eV})$ and that of $\mathrm{F}$ line $(14.7 \mathrm{eV})$ render questionable the use of helium as the actinometer gas. ${ }^{34}$ But we consider that with helium remaining the main component of the feed gas, the electron temperature in the auxiliary plasma should not significantly change with the variation of the minor components, which are $\mathrm{H}_{2}, \mathrm{NF}_{3}, \mathrm{NH}_{3}$, and radicals produced by their dissociation in the CCP plasma. Thus, assuming constant excitation cross section of species and neglecting the quenching of excited states by the gas, we apply the simplified actinometry equations: ${ }^{35,36}$

$$
\begin{gathered}
I_{706}=G \cdot K_{706} \cdot n_{e} \cdot[\mathrm{He}], \\
I_{F}=G \cdot n_{e} \cdot\left(K_{F} \cdot[\mathrm{F}]+K_{P F} \cdot\left[\mathrm{NF}_{3}\right]\right),
\end{gathered}
$$

where $G$ is a geometric factor, $[\mathrm{He}]$ and $[\mathrm{F}]$ are the densities of helium and $\mathrm{F}$ atoms, with $I_{706}$ and $I_{F}$ being their respective recorded intensities and $\left[\mathrm{NF}_{3}\right]$ is the remaining density of $\mathrm{NF}_{3}$ molecule in the $A P$, whose dissociative excitation can contribute to the production of $\mathrm{F}$ atom in the upper state of the $703.7 \mathrm{~nm}$ line, with $K_{F}$ being the corresponding rate coefficient. To write (6), the contribution to the $I_{F}$ intensity of the other dissociation products of the gas in the CCP, excepted F atoms, is neglected. The excitation coefficient $K_{P F}$ of the precursor molecule is deduced by measuring $I_{F}$ when known amount of the $\mathrm{NF}_{3}$, diluted in helium, is introduced into the reactor in the absence of the CCP discharge. And, as will be described in the following section, the density of precursor molecules $\mathrm{NF}_{3}$ in the downstream chamber, thus in the auxiliary plasma, can be measured by the $V U V-B B A S$. Hence, the contribution of $\mathrm{NF}_{3}$ molecules to the $I_{F}$ can be evaluated and subtracted for obtaining $I_{F}^{c}$, the intensity originated from the sole direct excitation of the ground state $\mathrm{F}$ atoms in the auxiliary plasma. And finally, the variation of the density of $F$ atoms in the downstream chamber, when changing the gas mixture and CCP discharge conditions, can be followed by using the simplified equation:

$$
[\mathrm{F}] \sim[\mathrm{He}] \frac{I_{F}^{c}}{I_{706}} .
$$

\section{Broad-band absorption spectroscopy}

The absolute densities of $\mathrm{NH}_{3}$ and $\mathrm{NF}_{3}$ molecules in the downstream chamber, thus their dissociation rates in the CCP chamber, as well as the density of HF molecules formed from the dissociation products, have been measured by the broadband absorption technique. ${ }^{31,37,38}$ A schematic of the top view of the reactor, with the VUV-BBAS setup is shown in Fig. 2. Shortly, the light source is a high-pressure deuterium $\left(\mathrm{D}_{2}\right)$ lamp (X2D2 from Hamamatsu) that emits a continuum radiation down to $120 \mathrm{~nm}$. A VUV grade parabolic mirror produces a collimated, $1 \mathrm{~cm}$ diameter, light beam at $90^{\circ}$ from the incident light. This VUV beam crosses the downstream chamber, through two optical ports facing each other and equipped with $\mathrm{MgF}_{2}$ windows, at about $5 \mathrm{~cm}$ below the

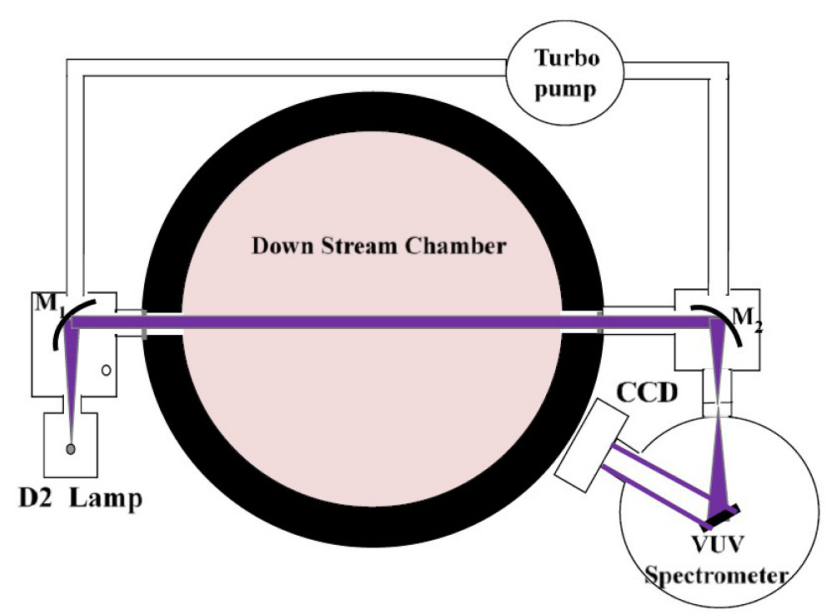

FIG. 2. Top view of the reactor showing the VUVAS experiment with the D2 light source and the VUV monochromator equipped with the CCD camera. 
shower head (see Fig. 1). At the exit of the second window, another VUV grade parabolic mirror focuses the VUV beam onto the entrance slit of a $20 \mathrm{~cm}$ focal length VUV spectrometer (Jobin-Yvon H20-UVL), equipped with a 1200 groove/mm concave VUV grating. The exit port of the spectrometer was modified to accept a VUV CCD camera (Newton DO940 for X-ray and VUV from Andor) with $2048 \times 512$ pixels of $13.5 \mu \mathrm{m}$ pitch size. In the central part of the CCD (between pixels 600-1500), the linear dispersion is $0.047 \mathrm{~nm} /$ pixel and the ultimate spectral resolution of the system is about $0.14 \mathrm{~nm}$ with a $20 \mu \mathrm{m}$ entrance slit width. But, the spectral resolution is degraded in the edges of the CCD. Turbomolecular pumps maintain a background pressure below $10^{-}$ ${ }^{4}$ Torr in the entire optical path of the VUV light outside the reactor chamber $\left(D_{2}\right.$ lamp to the reactor input window and the exit window to the CCD). As usual in BBAS experiments, ${ }^{38}$ the absorption spectra of the gas in the downstream chamber are obtained by recording three spectra with the CCD: (i) the background with the lamp off $(B G)$, (ii) the emission of the lamp without the gas flow, $L_{0}$, and (iii) the transmitted light of the lamp $\left[I_{\mathrm{P}}(\lambda)\right]$ with the gas flow On. We underline that the absence of energetic electrons in the DSC results in the absence of plasma emission, which can be neglected. The absorbance spectra $\left(A_{\lambda}\right)$, which is related to the wavelength dependent absorption cross-section $\sigma(\lambda)$ of the molecules through the Beer-Lambert law, is obtained by

$$
[A]_{\lambda}=\operatorname{Ln}\left(\frac{I_{0}(\lambda)}{I_{T}(\lambda)}\right)=\operatorname{Ln}\left(\frac{L_{0}(\lambda)-B G}{I_{P}(\lambda)-B G}\right)=\sum_{i} \sigma_{i}(\lambda) l N_{i}
$$

where $I_{0}$ and $I_{T}$ are the intensity of the incoming and transmitted VUV light, index " $i$ " refers to different absorbing species present in the chamber with density $N_{i}$, and $l$ is the absorption length. Although the absorption cross sections of $\mathrm{NH}_{3}$ (Refs. 39-42) and $\mathrm{NF}_{3}$ (Refs. 43-45) have been reported in the literature, for the determination of their partial pressures in the downstream chamber, we have used our own collection of absorbance spectra recorded when the reactor was filled with these gases at different known pressures in the absence of discharge. This collection of spectra constitutes some sort of reference tables. As an example, recorded absorbance spectra of $\mathrm{NH}_{3}$ and $\mathrm{NF}_{3}$ are reported in Figs. 3 and 4 for a few indicated pressures. This way of proceeding has the advantage of being insensitive to changes on the spectral profile of $\mathrm{NH}_{3}$ with the spectral resolution of the spectrograph + CCD. Opposite to the $\mathrm{NF}_{3}$ case, for which the VUV photon absorption ends up in a predissociated continuum, the upper states of the VUV transitions in $\mathrm{NH}_{3}$ are Rydberg states, with vibrational and rotational levels. In Fig. 3, transitions to these electronic states and corresponding vibrational levels are identified, but the rotational structure cannot be resolved. The absorption profile is thus composed of many narrow ro-vibrational transitions and important modifications on the behavior of the absorbance curves can be observed with the spectral resolution of the detection system (compare spectra in Refs. 40 and 42). It should be pointed out that the entrance slit of the spectrometer was kept unchanged and consequently, the spectral resolution was identical in all spectra recorded in plasma conditions and for the abacus. Also, using the calibration spectra of the abacus for the determination of $\mathrm{NH}_{3}$

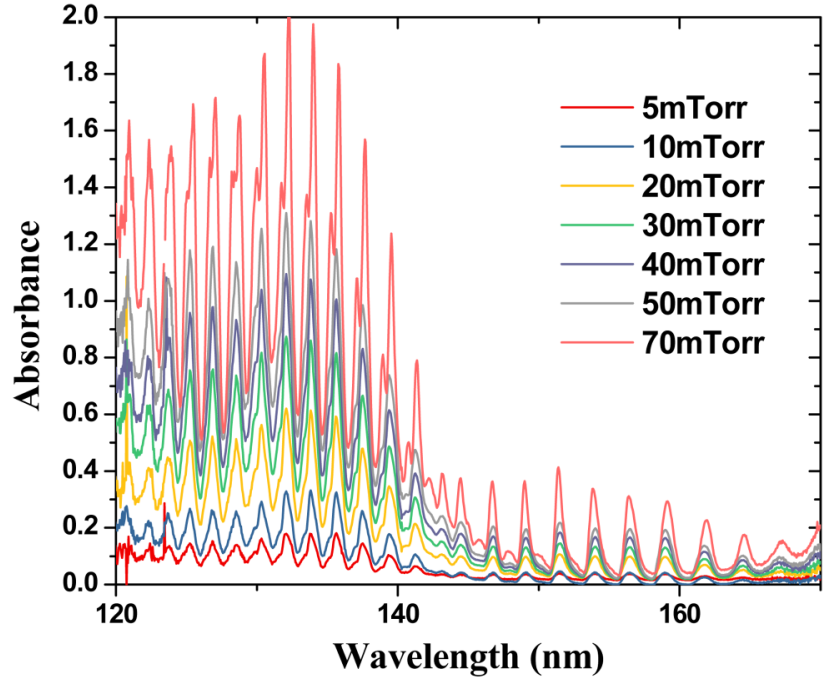

FIG. 3. VUV absorption spectrum of $\mathrm{NH}_{3}$ gas (no plasma) at several reactor filling pressures.

partial pressure under plasma conditions eliminates a possible error source by the saturation of the peak absorbancies. ${ }^{39}$

\section{RESULTS AND DISCUSSION}

\section{A. Characterization of HF spectrum}

Dissociation of $\mathrm{NF}_{3}$ in $\mathrm{CCP}$ plasma produces $\mathrm{F}$ atoms that can rapidly react with $\mathrm{H}$ containing molecules to form $\mathrm{HF}$ molecules. ${ }^{26,28}$ Strong absorption spectra of HF in the VUV spectral range have

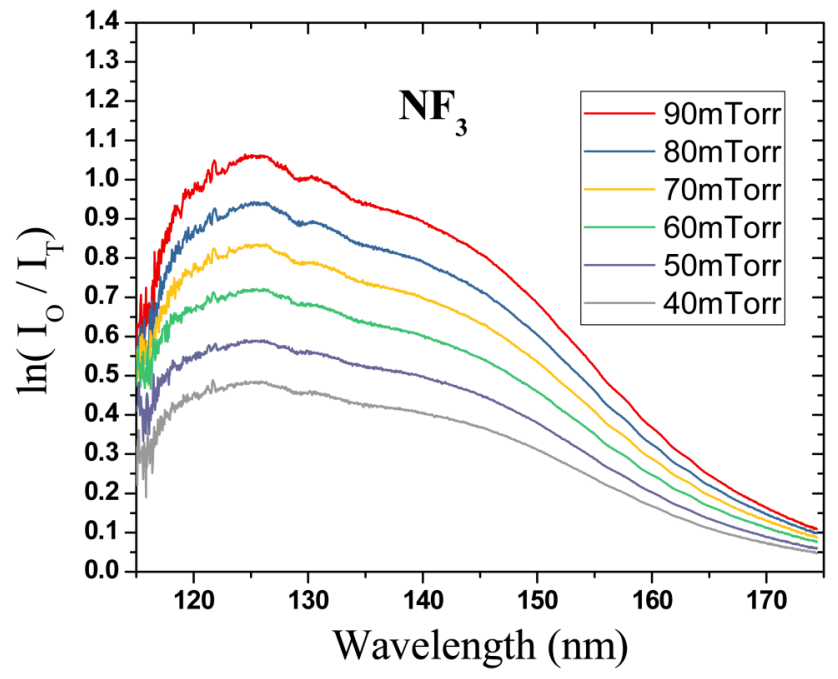

FIG. 4. VUV absorption spectrum of $\mathrm{NF}_{3}$ gas (no plasma) at several reactor filling pressures. 
been reported in the literature ${ }^{46,47}$ and its detection by VUV-BBAS was thus highly expected. The experiments have been carried out in the afterglow of $\mathrm{NF}_{3} / \mathrm{H}_{2}$ mixture in which $\mathrm{HF}$ is produced by the reaction of $\mathrm{F}$ atoms resulting from the plasma dissociation of $\mathrm{NF}_{3}$ with $\mathrm{H}_{2}$ molecules [reaction (2)], for which a rate coefficient $\mathrm{k}_{2}=2$ $-3 \times 10^{-17} \mathrm{~m}^{3} \mathrm{~s}^{-1}$ has been reported. ${ }^{26,28}$ Absorption spectra recorded in the downstream chamber without and with a discharge in the CCP chamber are shown in Fig. 5. The experimental steps are:

A mixture of $4 \% \mathrm{NF}_{3} / 9 \% \mathrm{H}_{2}$ diluted in helium is flown through the reactor and the exit throttle vale is adjusted for obtaining 1 Torr total pressure in the downstream chamber.

The recorded VUV spectra are identical to the one obtained at $40 \mathrm{mT}$ Torr of $\mathrm{NF}_{3}$ from the abacus of Fig. 4. As $\mathrm{NF}_{3}$ does not react

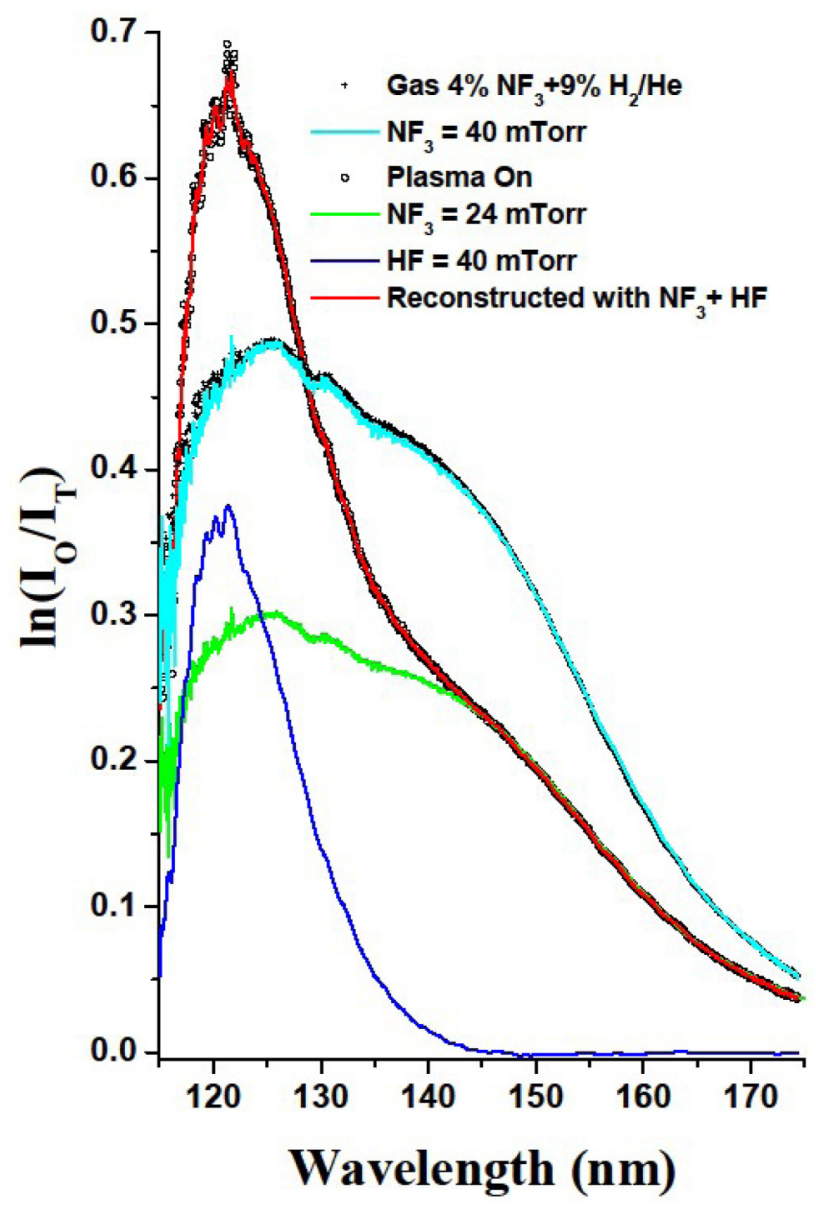

FIG. 5. Black cross (+): absorption spectra recorded in an $\mathrm{NF}_{3}(4 \%) / \mathrm{H}_{2}(9 \%) /$ $\mathrm{He}$ gas and adjusted with a pure $\mathrm{NF}_{3}$ spectrum recorded at 40 mTorr (cyan line). Black open circle $\left({ }^{\circ}\right)$ : absorption spectrum recorded with the plasma ON $(250 \mathrm{~W})$. This spectrum can be fitted in its high wavelength part by the green curve, which corresponds to $\mathrm{NF}_{3}$ gas at 24 mTorr. By subtracting this $\mathrm{NF}_{3}$ contribution to the overall spectrum, we obtain the VUV absorption spectrum of HF molecules (blue line), corresponding to a pressure of 40 mTorr HF according to its absorption cross section. with $\mathrm{H}_{2}$, we conclude that the partial pressure of $\mathrm{NF}_{3}$ in the DSC is $40 \mathrm{mT}$ in the absence of plasma.

A $250 \mathrm{~W}$ plasma is stuck in the CCP compartment and after a few seconds of stabilization time, a new VUV absorption spectrum is recorded. As seen in Fig. 5, the shape of this new spectrum is totally different from the previously recorded in the absence of CCP plasma. This modification revels absorption by new species formed under the CCP plasma action, which, as previously discussed, is an HF molecule. However, the high wavelength tail of the new spectrum can be fitted by the absorption spectrum of $\mathrm{NF}_{3}$ at a pressure of 24 mTorr, indicating that about the half of the $\mathrm{NF}_{3}$ molecules was dissociated by the CCP plasma. The new spectrum, obtained

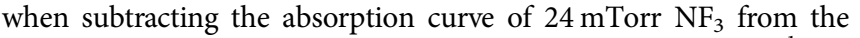
recorded spectra with the plasma $\mathrm{ON}$, corresponds to the $\mathrm{A}^{1} \Pi \leftarrow$ $\mathrm{X}^{1} \Sigma^{+}$absorption spectrum of HF molecules. This attribution is justified by the similarity of this spectrum with the one obtained by Nee et al. from synchrotron radiation absorption by HF gas. ${ }^{46}$ These authors also provide the wavelength dependent absorption cross section, from which the absorbance can be converted into the density of HF in the DSC by using Eq. (8). The deduced partial pressure of $\mathrm{HF}$ in the example presented in Fig. 5 is 40 mTorr. Given that $A^{1} \Pi$ state is predissociated, because its energy is above the $\mathrm{D}^{\circ}=5.87 \mathrm{eV}$ dissociation limit of $\mathrm{HF}^{48}$ the $\mathrm{HF}\left(\mathrm{A}^{1} \Pi \leftarrow \mathrm{X}^{1} \Sigma^{+}\right)$ absorption spectrum is a continuum, with its absorbance being scaled with the HF density, for a fixed absorption length. We will thus use in the following the absorbance spectrum deduced from $\mathrm{NF}_{3} / \mathrm{H}_{2}$ plasma, depicted in Fig. 5, for the determination of the amount of HF molecules produced in other plasma conditions.

As an example, in Fig. 6 are shown absorption spectra recorded in the downstream chamber without and with CCP plasma in $1.6 \% \mathrm{NF}_{3} / 2 \% \mathrm{NH}_{3}$ diluted in helium gas at a total flow rate of $21 / \mathrm{min}$ and 1 Torr pressure in the DSC. The spectrum recorded in the absence of CCP plasma results from absorption by only $\mathrm{NF}_{3}$ and $\mathrm{NH}_{3}$ and can be reconstructed by adding absorbance spectra from $16 \mathrm{mTorr}$ of $\mathrm{NF}_{3}$ and $20 \mathrm{mTorr}$ of $\mathrm{NH}_{3}$, which indicates their partial pressures in the DSC. Striking a $350 \mathrm{~W}, \mathrm{CCP}$ plasma results in an important diminution of the partial pressures of $\mathrm{NF}_{3}$ and $\mathrm{NH}_{3}$, which are highly dissociated by the discharge, and hence in weaker absorbance. The new absorption spectra with the CCP plasma ON can be reconstructed by adding absorbance spectra of $7.7 \mathrm{mT}$ of $\mathrm{NF}_{3}, 4 \mathrm{mT}$ of $\mathrm{NH}_{3}$, and $20 \mathrm{mT}$ of HF. Thus, about $50 \%$ of $\mathrm{NF}_{3}$ and $80 \%$ of $\mathrm{NH}_{3}$ of the introduced gas have been dissociated by the plasma and, as will be discussed in following sections, the chain reactions of the dissociation products lead to the formation of HF molecules.

The partial pressures of $\mathrm{NF}_{3}, \mathrm{NH}_{3}$, and $\mathrm{HF}$ in all gas mixtures and plasma conditions have been deduced like in Fig. 6, by the best adjustment of the recorded absorption spectrum with the sum of three absorbance curves of these molecules with adequate amplitudes. Considering the reproducibility of results from several experiments, the uncertainty on determined partial pressures is estimated to be about $7 \%$ of the evaluated values plus 1 mTorr.

\section{B. Kinetics of $\mathrm{NF}_{3} / \mathrm{H}_{2}$ plasmas}

Dissociation of $\mathrm{NF}_{3}$ in the CCP plasma produces also $\mathrm{NF}_{2}$ and $\mathrm{NF}$ radicals that rapidly react with $\mathrm{H}$ atoms, produced by the 


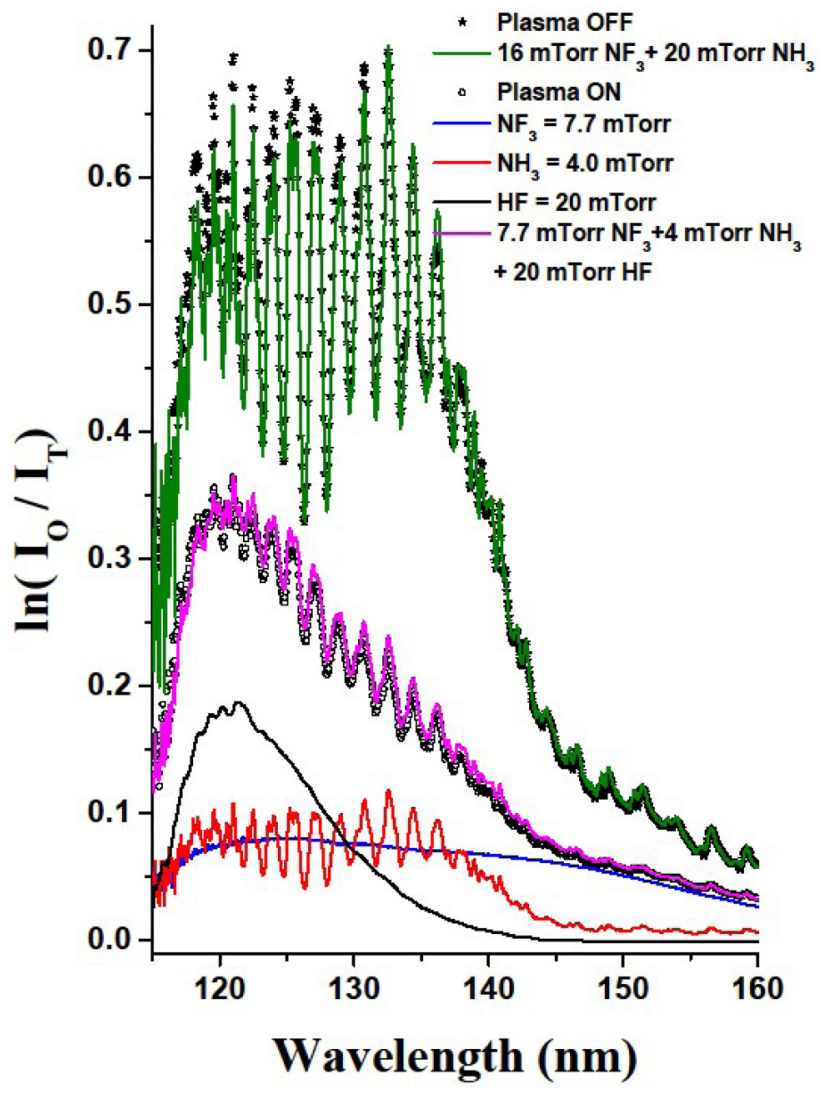

FIG. 6. Black aster $\left(^{*}\right.$ ): absorption spectra recorded in an $\mathrm{NF}_{3} / \mathrm{NH}_{3} / \mathrm{He}$ gas mixture gas/He gas and adjusted (green line) with the spectra from the abaques with the sum of $16 \mathrm{mTorr}$ of $\mathrm{NF}_{3}$ and $20 \mathrm{mTorr}$ of $\mathrm{NH}_{3}$. Black open circle: absorption spectrum recorded with the plasma ON $(250 \mathrm{~W})$. This spectrum can be fitted by the sum of three spectra: HF (20 mTorr), NF3 (7.7 mTorr), and $\mathrm{NH}_{3}$ (4 mTorr).

dissociation of $\mathrm{H}_{2}$ in the CCP, but also reaction (2). The chain reactions which follow are

$$
\begin{gathered}
\mathrm{H}+\mathrm{NF}_{2} \rightarrow \mathrm{NF}+\mathrm{HF}, \\
\mathrm{H}+\mathrm{NF} \rightarrow \mathrm{N}+\mathrm{HF}, \\
\mathrm{NF}+\mathrm{NF} \rightarrow \mathrm{N}_{2}+2 \mathrm{~F},
\end{gathered}
$$

for which the rate coefficients reported in the literature are $k_{9}=1.9 \times 10^{-17} \mathrm{~m}^{3} \mathrm{~s}^{-1} ;{ }^{49} k_{10}=2.5 \times 10^{-17} \mathrm{~m}^{3} \mathrm{~s}^{-1}$ (Refs. 49 and 50), and $k_{11}=7 \times 10^{-17} \mathrm{~m}^{3} \mathrm{~s}^{-1}$ (Refs. 49 and 50). These fast chain reactions, whose main final product is HF molecule, can continue as far there are enough $\mathrm{H}_{2}$ molecules and/or CCP generated $\mathrm{F}$ atoms in the chamber. Figure 7 illustrates the consumption of plasma generated $\mathrm{F}$ atoms and production of $\mathrm{HF}$ in $\mathrm{NF}_{3} / \mathrm{H}_{2} / \mathrm{He}(100 / 100 /$ 1900 SCCM) gas mixture and pressure fixed at 1 Torr in the DSC.
With increasing RF power of the CCP, the steady-state partial pressure of $\mathrm{NF}_{3}$ in the downstream chamber drops gradually from its initial value of $52 \mathrm{mT}$ Torr to $20 \mathrm{mTorr}$ at $350 \mathrm{~W}$. Simultaneously, the partial pressure of produced HF molecules increases, reaching $90 \mathrm{mTorr}$ at $350 \mathrm{~W}$. It is also shown in this figure the ratio between the partial pressure of $\mathrm{HF}$ and the missing partial pressure of $\mathrm{NF}_{3}$. This ratio clearly shows that three HF molecules are produced for one missing $\mathrm{NF}_{3}$ molecule, indicating that once an $\mathrm{NF}_{3}$ molecule starts to be dissociated, producing the first $\mathrm{F}$ atom, the chain reactions (2) and (9)-(11) will consume the other by-products of the dissociation $\left(\mathrm{NF}_{2}\right.$ and $\left.\mathrm{NF}\right)$ to form $\mathrm{HF}$ molecules. In the above presented example, the limiting factor of the chain reactions is the amount of the plasma dissociated $\mathrm{NF}_{3}$ molecules, which depends on $\mathrm{RF}$ power. Higher is the RF power, larger is the dissociation rate of $\mathrm{NF}_{3}$ and larger is the amount of produced HF. However, the limiting factor can also be the amount of $\mathrm{H}$ atoms, produced by the plasma dissociation of $\mathrm{H}_{2}$ molecules or by reaction (2), available for the chain reactions. In Fig. 8 are reported the partial pressures of $\mathrm{NF}_{3}$ and $\mathrm{HF}$ in the DSC versus the amount of $\mathrm{H}_{2}$ in the feed gas, composed of $100 \mathrm{SCCM}$ of $\mathrm{NF}_{3}, x \mathrm{SCCM}$ of $\mathrm{H}_{2}$ and 1900 $--x$ SCCM of helium. The RF power in the CCP is fixed at $250 \mathrm{~W}$ and the total pressure in the DSC is 1 Torr. At the beginning, with increasing $\mathrm{H}_{2}$ flow rate, the partial pressure of $\mathrm{HF}$ increases almost linearly to reach its maximum at about $100 \mathrm{SCCM}$ of $\mathrm{H}_{2}$, while $\mathrm{NF}_{3}$ density remains almost constant. In fact, the dissociation rate of $\mathrm{NF}_{3}$, thus the amount of $\mathrm{F}$ atoms in the DSC is fixed by the RF power in the CCP and up to 100 SCCM of $\mathrm{H}_{2}$ the total number of $\mathrm{F}$ atoms resulting from the dissociation of $\mathrm{NF}_{3}$ exceeds the double of the number of introduced $\mathrm{H}_{2}$ molecules. Thus, every $\mathrm{H}_{2}$ of the feed gas produces two HF molecules. This is seen from the linear increase of the ratio $\left(\mathrm{HF} /\right.$ dissociated $\mathrm{NF}_{3}$ ) during the initial phase of the $\mathrm{H}_{2}$ flow rate rise, also shown in Fig. 8. The actinometric emission intensity of the $703.7 \mathrm{~nm} F$ line in the auxiliary plasma, which is indicative of the partial pressure of fluorine atoms in the

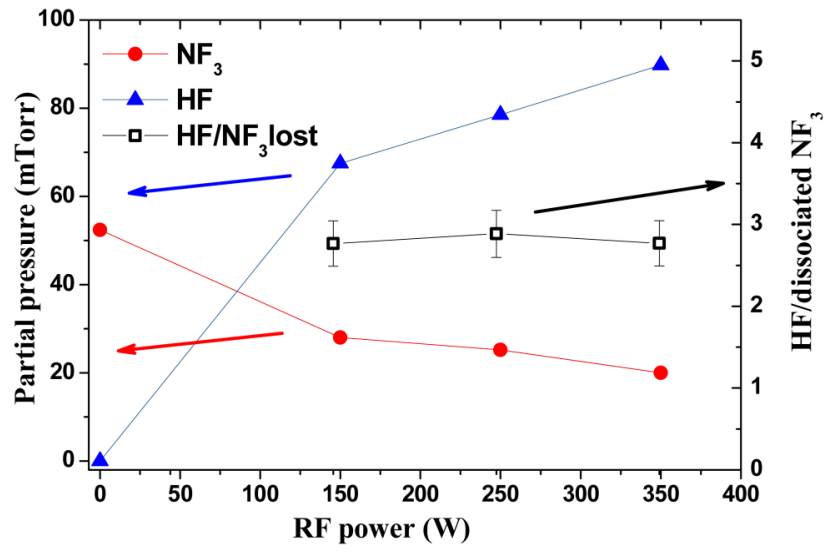

FIG. 7. Variations of the densities of $\mathrm{HF}$ and $\mathrm{NF}_{3}$ as a function of the RF power in $\mathrm{NF}_{3} / \mathrm{H}_{2}$ plasmas. The hollow black squares show the ratio of the $\mathrm{HF}$ density divided by the density of $\mathrm{NF}_{3}$ which is lost when the plasma is $\mathrm{ON}$, indicating that each lost $\mathrm{NF}_{3}$ leads to the formation of $3 \mathrm{HF}$ molecules. 


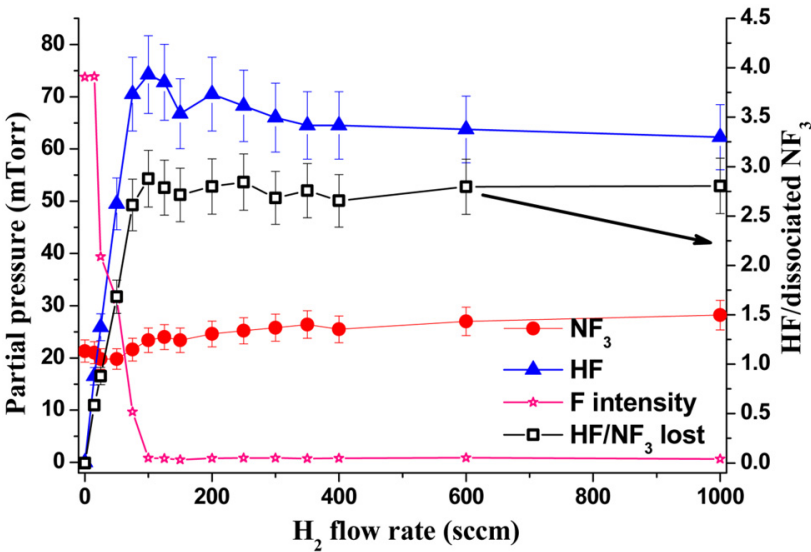

FIG. 8. Impact of the $\mathrm{H}_{2}$ dilution in $\mathrm{NF}_{3}$ on the densities of $\mathrm{NF}_{3}, \mathrm{HF}, \mathrm{F}$, and on the ratio of produced $\mathrm{HF}$ per lost $\mathrm{NF}_{3}$.

DSC, is also plotted in Fig. 8. Its behavior indicates that, as expected, the density of $\mathrm{F}$ atoms in the DSC decreases as the $\mathrm{H}_{2}$ flow rate increases up to about 100 SCCM. Above this value, there are enough $\mathrm{H}_{2}$ molecules in the reactor to consume all $\mathrm{F}$ atoms of the dissociated $\mathrm{NF}_{3}$ molecules, and the intensity of the 703.7 fluorine line from the auxiliary plasma remains zero.

In conclusion, below $100 \mathrm{SCCM}$ of $\mathrm{H}_{2}$, this is the amount of $\mathrm{H}_{2}$ molecules of the feed gas which limits the quantity of HF produced inside the reactor but above 100 SCCM, the dissociation rate of $\mathrm{NF}_{3}$ will become the limiting factor. However, as the amount of $\mathrm{H}_{2}$ in the feed gas becomes significant, its vibrational and rotational excitation will lead to a slight lowering of the electron temperature in the CCP plasma, resulting in a small diminution of the dissociation rate of $\mathrm{NF}_{3}$. This is the reason for the small enhancement of the partial pressure of $\mathrm{NF}_{3}$ after its minimum density at $100 \mathrm{SCCM}$ of $\mathrm{H}_{2}$ and the simultaneous lowering of the HF density, as seen in Fig. 8. However, the ratio of the partial pressures of HF over the dissociated $\mathrm{NF}_{3}$ remains close to 3 , attesting that any of $\mathrm{NF}_{3}$ molecules that starts to be dissociated by losing a flour atom, is fully consumed by the chain reactions (2) and (9)-(11) to form, in the end, three HF molecules.

\section{Kinetics of $\mathrm{NF}_{3} / \mathrm{NH}_{3}$ plasmas}

$\mathrm{F}$ and $\mathrm{H}$ atoms produced in the CCP chamber by the dissociation of $\mathrm{NF}_{3}$ and $\mathrm{NH}_{3}$, trigger a series of chain reactions which leads to the production of large amount of HF molecules. In Table I are reported the measured partial pressures of $\mathrm{NF}_{3}, \mathrm{NH}_{3}$, and $\mathrm{HF}$ in the gas introduced into the reactor chamber (plasma off, $0 \mathrm{~W}$ ) and for three different RF powers. The introduced gas mixture is $\mathrm{NF}_{3} / \mathrm{NH}_{3} / \mathrm{He}(50 / 50 / 1950 \mathrm{SCCM})$ and the pressure in the $D S C$ is fixed to 1 Torr. In the absence of plasma, the partial pressures of $\mathrm{NF}_{3}$ and $\mathrm{NH}_{3}$ are 25 and 27 mTorr, respectively. Striking the CCP plasma in the upper chamber with $150 \mathrm{~W}$ RF power results in a drastic decrease (by factor 7) of the $\mathrm{NH}_{3}$ partial pressure in the downstream chamber, whereas that of $\mathrm{NF}_{3}$ is only divided by 2 . This different behavior is opposite to an expectation based on binding energy of $\mathrm{F}$ atom in $\mathrm{NF}_{3}(2.9 \mathrm{eV})$ and $\mathrm{H}$ atoms in $\mathrm{NH}_{3}(4.1 \mathrm{eV})$, which should favor a higher dissociation rate of the former. But, the difference reflects the fact that electron impact is the only process responsible for the dissociation of $\mathrm{NF}_{3}$ molecules, whereas the so produced $\mathrm{F}$ atoms can also react with $\mathrm{NH}_{3}$, according to reactions (4) and (12), $10,15,51,52$

$$
\mathrm{HF}+\mathrm{NH}_{3} \rightarrow \mathrm{NH}_{4} \mathrm{~F}
$$

Reaction (4), which is very fast with $\mathrm{k}_{4}=1-4 \times 10^{-16} \mathrm{~m}^{-3} \mathrm{~s}^{-1}$ according to the litterature, ${ }^{30}$ can explain why the newly generated HF molecule, with its partial pressure of $28 \mathrm{mTorr}$, becomes the most abundant molecule in the DSC at the lowest $150 \mathrm{~W}$ of CCP power.

With increasing RF power, thus increasing plasma density in the CCP chamber, $\mathrm{NF}_{3}$ and $\mathrm{NH}_{3}$ are more dissociated but the enhancement of their dissociated parts, also reported in columns 5 and 7 of Table I, is much slowed down. Accordingly, the amount of the produced HF increases, but it seems to levels off above $300 \mathrm{~W}$ RF power. We note that when RF power exceeds $150 \mathrm{~W}$, due to the excess of plasma generated $\mathrm{H}$ atoms, all $\mathrm{F}$ atoms produced by the dissociation of $\mathrm{NF}_{3}$ are converted to $\mathrm{HF}$ molecules.

Figure 9 shows the impact of the $\mathrm{NH}_{3}$ dilution (for a fixed $\mathrm{NF}_{3}$ flow rate of 50 SCCM and total flow rate of 2050 SCCM at $250 \mathrm{~W}$ CCP power) on the densities of $\mathrm{NH}_{3}, \mathrm{NF}_{3}, \mathrm{HF}$, and also on the amount of $\mathrm{NH}_{3}$ and $\mathrm{NF}_{3}$ lost (compared to the plasma OFF). The amount of $\mathrm{NF}_{3}$ lost is multiplied by a factor of 3 in this figure to highlight the relationship between the HF density and the amount of $\mathrm{F}$ produced by $\mathrm{NF}_{3}$ dissociation (assuming that $3 \mathrm{~F}$ atoms are produced for each $\mathrm{NF}_{3}$ lost, as previously observed in $\mathrm{NF}_{3} / \mathrm{H}_{2}$ plasmas). The variation of $\mathrm{F}$ is not shown because it drops rapidly below the detection limit as soon as $25 \mathrm{SCCM}$ of $\mathrm{NH}_{3}$ is added to $\mathrm{NF}_{3}$. The density of $\mathrm{NF}_{3}$, whose gas flow rate is constant at $50 \mathrm{SCCM}$, is increasing slowly with the amount of $\mathrm{NH}_{3}$ injected in the discharge. This is attributed to the small decay of the electron temperature/density with increasing $\mathrm{NH}_{3}$ density in the mixture, as well as with a change of its loss rate by pumping when modifying the gas mixture. Indeed, as a consequence of the molecular mass dependence of the pumping speed, the density of $\mathrm{NF}_{3}$ without plasma (not shown) is also slightly increased when changing the $\mathrm{NH}_{3}$ dilution from 100 to 400 SCCM. As a result, with the CCD plasma on, the amount of $\mathrm{NF}_{3}$ lost is almost not varying for the $\mathrm{NH}_{3}$ flow rate ranging between 100 and 400 SCCM. The density of $\mathrm{HF}$ rises rapidly to reach a maximum value at $50 \mathrm{SCCM} \mathrm{NH}$, while at the same time, the $\mathrm{NH}_{3}$ density remains negligibly low. This behavior is in good agreement with the results of Table I and with reaction (4): $\mathrm{F}$ atoms produced from $\mathrm{NF}_{3}$ dissociation react rapidly with $\mathrm{NH}_{3}$ to produce $\mathrm{HF}$. As far there is enough $\mathrm{F}$ available, all the injected $\mathrm{NH}_{3}$ molecules are consumed by reaction (4) and the HF density rises accordingly. $\mathrm{NH}_{3}$ is fully dissociated for its flow up to approximately 50 SCCM, at which point there is no more $\mathrm{F}$ atoms available: the $\mathrm{NH}_{3}$ density then increases and above $75 \mathrm{SCCM}$ it raises almost linearly with the $\mathrm{NH}_{3}$ flow rate. Surprisingly, the HF density appears to decay significantly when the $\mathrm{NH}_{3}$ flow rate overpass about 50 SCCM: once all $\mathrm{F}$ atoms available are consumed by $\mathrm{NH}_{3}$ to form $\mathrm{HF}$, one would expect the $\mathrm{HF}$ density to reach a steady state. A fraction of this decay can be 
TABLE I. Measured partial pressures of $\mathrm{NF}_{3}, \mathrm{NH}_{3}$, and $\mathrm{HF}$ at different $\mathrm{RF}$ powers of $\mathrm{CCP}$, together with dissociated parts of $\mathrm{NF}_{3}$ and $\mathrm{NH}_{3}$ and the ratios of $\mathrm{HF}$ over dissociated parts.

\begin{tabular}{|c|c|c|c|c|c|c|c|}
\hline $\begin{array}{l}\text { RF power } \\
(\mathrm{W})\end{array}$ & $\begin{array}{c}\text { Measured } \mathrm{NF}_{3} \\
(\mathrm{mT})\end{array}$ & $\begin{array}{c}\text { Measured } \mathrm{NH}_{3} \\
(\mathrm{mT}) \\
\end{array}$ & $\begin{array}{c}\text { Measured HF } \\
(\mathrm{mT})\end{array}$ & $\begin{array}{c}\text { Dissociated } \mathrm{NF}_{3} \\
(\mathrm{mT})\end{array}$ & $\begin{array}{c}\mathrm{HF} / \text { missing } \\
\mathrm{NF}_{3}\end{array}$ & $\begin{array}{c}\text { Dissociated } \mathrm{NH}_{3} \\
(\mathrm{mT})\end{array}$ & $\begin{array}{c}\mathrm{HF} / \text { missing } \\
\mathrm{NH}_{3} \\
\end{array}$ \\
\hline 0 & 25 & 27 & 0 & 0 & & 0 & \\
\hline 150 & 12 & 4 & 28 & 13 & 2.2 & 23 & 1.2 \\
\hline 250 & 10 & 3 & 44 & 15 & 2.9 & 24 & 1.8 \\
\hline 350 & 9 & 1,5 & 48 & 16 & 3.0 & 25.5 & 1.9 \\
\hline
\end{tabular}

attributed to the fact that less $\mathrm{NF}_{3}$ is dissociated when the $\mathrm{NH}_{3}$ gas flow rate is increased (as previously observed in $\mathrm{NF}_{3} / \mathrm{H}_{2}$ mixtures, Fig. 8) but this is far from being enough to explain the observed HF density decay. Indeed, the ratio $\mathrm{NF}_{3}$ loss/HF drops from about 3 at $50 \mathrm{SCCM} \mathrm{NH} \mathrm{NH}_{3}$ to 1.8 at $400 \mathrm{SCCM}$ of $\mathrm{NH}_{3}$, suggesting that a significant part of the HF produced is lost by a new mechanism. Furthermore, the amount of $\mathrm{NH}_{3}$ lost would also be expected to be constant for the same reason, although it shows a significant increase with the $\mathrm{NH}_{3}$ flow rate. As a matter of fact, there seems to be a correlation between the amount of $\mathrm{NH}_{3}$ lost and the amount of $\mathrm{HF}$ decreases after its maximum at $50 \mathrm{SCCM}$ of $\mathrm{NH}_{3}$ when its flow rate increases above 75 SCCM. All these observations are strongly suggesting that reaction (12) is taking place efficiently under our conditions, i.e., that $\mathrm{NH}_{3}$ reacts with $\mathrm{HF}$ to produce $\mathrm{NH}_{4} \mathrm{~F}$, which is believed to be one of the main precursors for the formation of salts on the wafer. This reaction, which is used to produce $\mathrm{NH}_{4} \mathrm{~F}$ commercially, ${ }^{53}$ is fully reversible. But since $\mathrm{NH}_{4} \mathrm{~F}$ is poorly volatile at low temperatures, it will then condense efficiently on cold enough surfaces to form a crystal. Furthermore, at one Torr pressure, three body recombination reactions can proceed at high enough rates (especially between large size molecules, which can share the excess energy of the reaction between a large number of available

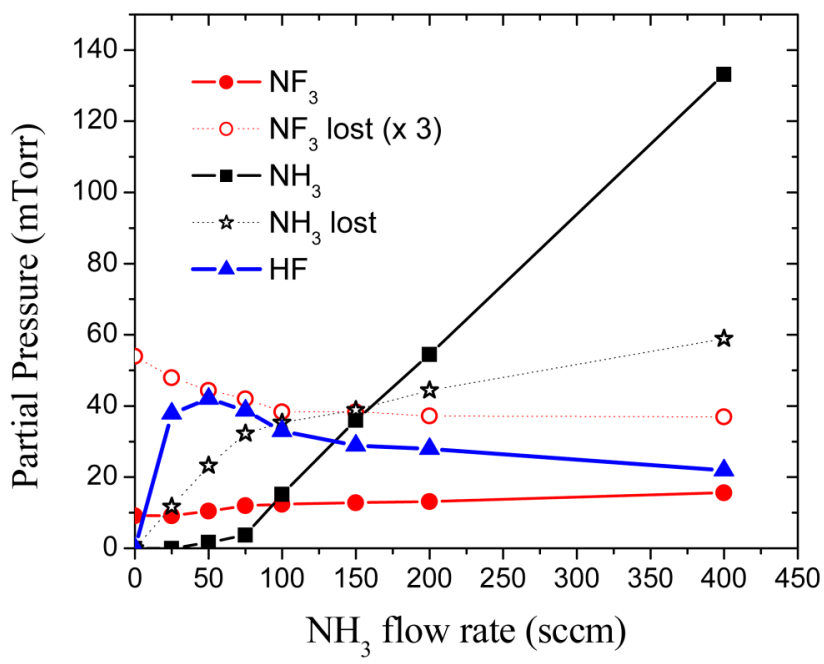

FIG. 9. Impact of the $\mathrm{NH}_{3}$ flow rate in $\mathrm{He} / \mathrm{NF}_{3}$ (50 SCCM flow rate) plasma on the densities of $\mathrm{NF}_{3}, \mathrm{NH}_{3}, \mathrm{HF}$ and on the amount of the lost $\mathrm{NH}_{3}$ and $\mathrm{NF}_{3}$ when the plasma is $\mathrm{ON}$ with a $250 \mathrm{~W}$ RF power. bonds). It is thus reasonable to assume that reaction (12) producing $\mathrm{NH}_{4} \mathrm{~F}$ take place under our experimental conditions, even if this remains speculative since $\mathrm{NH}_{4} \mathrm{~F}$ is not directly observed. Thus, the $\mathrm{NH}_{4} \mathrm{~F}$ density can be roughly estimated from the loss of $\mathrm{HF}$ (accounting for the reduced $\mathrm{NF}_{3}$ loss) or directly from the loss of $\mathrm{NH}_{3}$, as shown in Fig. 10. We observe a qualitative agreement between the two estimations, although a significant quantitative divergence is observed at high $\mathrm{NH}_{3}$ dilution, where the $\mathrm{NH}_{4} \mathrm{~F}$ density deduced from $\mathrm{NH}_{3}$ loss is significantly larger (more than a factor of two) than that deduced from HF decrease. This is probably due to the assumption that the $\mathrm{NH}_{3}$ loss is caused solely by reactions with HF: the $\mathrm{NH}_{3}$ density is actually driven by several processes, including, for example, the recombination $\mathrm{NH}_{2}+\mathrm{H} \rightarrow \mathrm{NH}_{3}$, which depend on the $\mathrm{H}$ density and thus on the $\mathrm{H}$ atoms recombination rate on the reactor walls to form $\mathrm{H}_{2}$ (which may be plasma chemistry dependent). Nevertheless, our results are suggesting that significant amount of $\mathrm{NH}_{4} \mathrm{~F}$ is produced in the discharge at large $\mathrm{NH}_{3}$ dilutions, i.e., the processing conditions used to form salts on the wafer in industrial etching processes. ${ }^{22}$

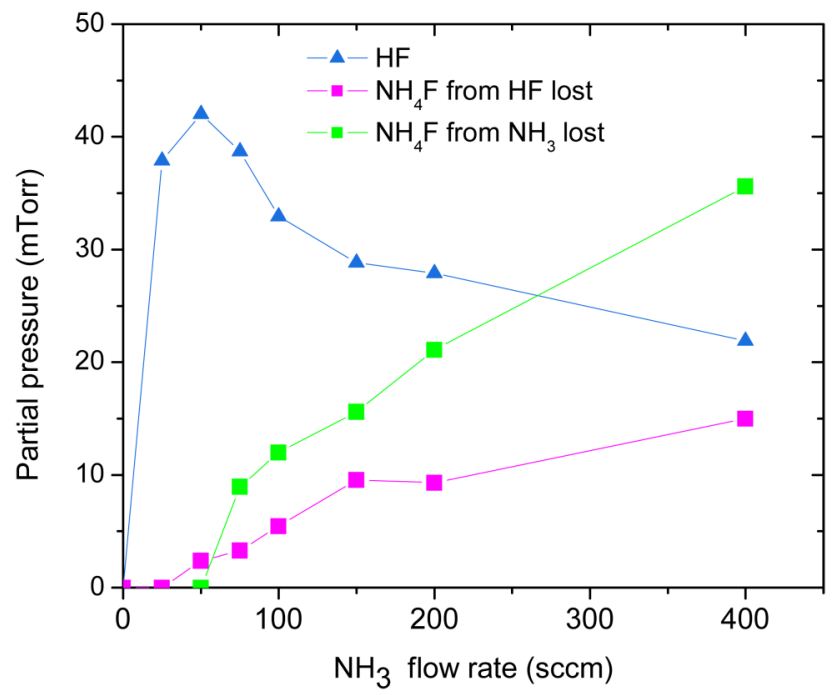

FIG. 10. Variation of the HF density as a function of the $\mathrm{NH}_{3}$ dilution, under conditions of Fig. 9. The magenta and green curves indicate the density of $\mathrm{NH}_{4} \mathrm{~F}$ deduced, respectively, from the loss of $\mathrm{HF}$ and from the loss of $\mathrm{NH}_{3}$ (assuming that $\mathrm{NH}_{3}$ reacts with $\mathrm{HF}$ to form $\mathrm{NH}_{4} \mathrm{~F}$ ). 


\section{CONCLUSIONS}

The chemistry of downstream plasmas used for isotropic etching of Si alloys is investigated by VUV absorption spectroscopy and $\mathrm{OES}$ both in $\mathrm{NF}_{3} / \mathrm{H}_{2}$ and $\mathrm{NF}_{3} / \mathrm{NH}_{3}$ chemistries. In both cases, VUVAS indicates the formation of large amounts of HF molecules which are expected to play a role in oxide etching. $\mathrm{F}$ atoms are shown to react rapidly with $\mathrm{H}_{2}$ and $\mathrm{NH}_{3}$ to produce $\mathrm{HF}$ until all the fluorine is consumed. Also, $\mathrm{H}$ rapidly reacts with $\mathrm{NF}_{2}$ and $\mathrm{NF}$ for producing $\mathrm{HF}$ and consuming $\mathrm{NF}_{\mathrm{x}}$ radicals, which could not be detected by UVAS in the downstream chamber. In the $\mathrm{NF}_{3} / \mathrm{NH}_{3}$ chemistry, the HF density is shown to decrease when the $\mathrm{NH}_{3}$ flow rate is increased above the $\mathrm{NF}_{3}$ flow rate. This decay scales with the amount of $\mathrm{NH}_{3}$ that is lost, which is attributed to an efficient reaction between $\mathrm{NH}_{3}$ and $\mathrm{HF}$ to form the $\mathrm{NH}_{4} \mathrm{~F}$ molecule that is supposed to be the precursor for salt formation on the wafer. Though $\mathrm{NH}_{4} \mathrm{~F}$ was not directly observed in the plasma, its density could be estimated based on the quantity of $\mathrm{HF}$ and the lost $\mathrm{NH}_{3}$.

\section{ACKNOWLEDGMENTS}

This work was partly supported by the LabEx Minos (No. ANR-10-LABX-55-01) and by the French RENATECH network. The authors would like to acknowledge Applied Materials for their technical support.

\section{REFERENCES}

${ }^{1}$ S. M. Irving, Solid State Technol. 14, 47 (1971).

${ }^{2}$ V. M. Donnelly and A. Kornblit, J. Vac. Sci. Technol. A 31, 050825 (2013).

${ }^{3}$ C. T. Carver, J. Plombon, P. E. Romero, S. Suri, T. A. Tronic, and R. B. Turkot, Jr., ECS J. Solid State Sci. Technol. 4, N5005 (2015).

${ }^{4}$ J. Jang et al., 2009 Symposium on VLSI Technology, Honolulu, HI, 15-17 June 2009 (IEEE, Honolulu, 2009), p. 192.

${ }^{5}$ E. Prévost, G. Cunge, C. De-Buttet, S. Lagrasta, L. Vallier, and C. Petit-Etienne, Proc. SPIE 10149, 101490M (2017).

${ }^{6}$ N. Posseme, O. Pollet, and S. Barnola, Appl. Phys. Lett. 105, 051605 (2014).

${ }^{7}$ E.-J. Song, J.-H. Kim, J.-D. Kwon, S.-H. Kwon, and J.-H. Ahn, Jpn. J. Appl. Phys. 57, 106505 (2018).

${ }^{8}$ S. Huang, V. Volynets, J. R. Hamilton, S.-K. Nam, I.-C. Song, S. Lu, J. Tennyson, and M. J. Kushner, J. Vac. Sci. Technol. A 36, 021305 (2018).

${ }^{9}$ B. E. E. Kastenmeier, P. J. Matsuo, G. S. Oehrlein, and J. G. Langan, J. Vac. Sci. Technol. A 16, 2047 (1998).

${ }^{10}$ H. Nishino, N. Hayasaka, and H. Okano, J. Appl. Phys. 74, 1345 (1993).

${ }^{11}$ M. T. Suzuki, J. Kikuchi, M. Nagasaka, and S. Fujimura, Mater. Res. Soc. Symp. Proc. 477, 167 (1997).

${ }^{12}$ W. S. Kim, W. G. Hwang, I. K. Kim, K. Y. Yun, K. M. Lee, and S. K. Chae, Solid State Phenom. 103, 63 (2005).

${ }^{13}$ Y. Hagimoto, H. Ugajin, D. Miyakoshi, H. Iwamoto, Y. Muraki, and T. Orii, Solid State Phenom. 134, 7 (2008).

${ }^{14}$ T. Kusuki, H. Kawakami, H. Sakaue, and Y. Horiike, Extended Abstracts of Electrochemical Society Meeting, Honolulu, HI, 16-21 May 1993 (IOPP, Honolulu, 1993), p. 375.

${ }^{15} \mathrm{H}$. Ogawa, T. Arai, M. Yanagisawa, T. Ichiki, and Y. Horiike, Jpn. J. Appl. Phys. 41, 5349 (2002).

${ }^{16}$ A. J. Sidhwa, F. C. Goh, H. A. Naseem, and W. D. Brown, J. Vac. Sci. Technol. A 11, 1156 (1993).

${ }^{{ }^{17}}$ K. Shinoda, N. M. H. Kobayashi, M. Izawa, T. Saeki, K. Ishikawa, and M. Hori, J. Vac. Sci. Technol. A. 37, 051002 (2019).
${ }^{18}$ V. Martirosyan, E. Despiau-Pujo, J. Dubois, G. Cunge, and O. Joubert, J. Vac. Sci. Technol. A 36, 041301 (2018).

${ }^{19}$ V. Martirosyan, O. Joubert, and E. Despiau-Pujo, J. Phys. D Appl. Phys. 52, 055204 (2018).

${ }^{20}$ V. Ah-Leung, O. Pollet, N. Possémé, M. Garcia, B. Névine Rochat, C. Guedj, G. Audoit, and S. Barnola, J. Vac. Sci. Technol. A 35, 021408 (2017).

${ }^{21}$ N. Posseme, V. Ah-Leung, O. Pollet, C. Arvet, and M. Garcia-Barros, J. Vac. Sci. Technol. A 34, 061301 (2016).

${ }^{22}$ V. Renaud, C. Petit-Etienne, J.-P. Barnes, J. Bisserier, O. Joubert, and E. Pargon, J. Appl. Phys. 126, 243301 (2019).

${ }^{23}$ A. Tavernier, L. Favennec, T. Chevolleau, and V. Jousseaume, ECS Trans. 45, 225 (2012)

${ }^{\mathbf{2 4}}$ H. J. Oh, J. H. Lee, M. S. Lee, W. G. Shin, S. Y. Kang, G. D. Kim, and D. H. Ko, ECS Trans. 61, 1 (2014).

${ }^{25}$ M. A. A. Clyne, D. J. McKenney, and R. F. Walker, Can. J. Chem. 51, 3596 (1973).

${ }^{26}$ R. F. Heidner, J. F. Bott, C. E. Gardner, and J. E. Melzer, J. Chem. Phys. 70, 4509 (1979).

${ }^{27}$ K. H. Homann, W. C. Solomon, J. Warnatz, H. G. Wagner, and C. Zetzsch, Ber. Bunsenges. Phys. Chem. 74, 585 (1970).

${ }^{28}$ E. E. Wurzburg and P. L. Houston, J. Chem. Phys. 72, 4811 (1980).

${ }^{29}$ J. M. Herbelin and N. Cohen, Chem. Phys. Lett. 20, 605 (1973).

${ }^{30}$ L. Tian, Y. Zhu, H. Song, and M. Yang, Phys. Chem. Chem. Phys. 21, 11385 (2019).

${ }^{31}$ G. Cunge, M. Fouchier, M. Brihoum, P. Bodart, M. Touzeau, and N. Sadeghi, J. Phys. D Appl. Phys. 44, 122001 (2011).

${ }^{32}$ G. Cunge, P. Bodart, M. Brihoum, F. Boulard, T. Chevolleau, and N. Sadeghi, Plasma Sources Sci. Technol. 21, 4006 (2012).

${ }^{33}$ J. W. Coburn and H. F. Winters, J. Vac. Sci. Technol. 16, 391 (1979).

${ }^{34}$ V. M. Donnelly and M. J. Schabel, J. Appl. Phys. 91, 6288 (2002).

${ }^{35}$ J.-P. Booth, O. Joubert, J. Pelletier, and N. Sadeghi, J. Appl. Phys. 69, 618 (1991).

${ }^{36}$ J.-P. Booth and N. Sadeghi, J. Appl. Phys. 70, 611 (1991).

37. J.-P. Booth and G. Cunge, F. Neuilly, and N. Sadeghi, Plasma Sources Sci. Technol. 7, 423 (1998).

${ }^{38}$ M. Kogelschatz, G. Cunge, and N. Sadeghi, J. Phys. D Appl. Phys. 37, 1954 (2004).

${ }^{39}$ B. M. Cheng, H. C. Lu, H. K. Chen, M. Bahou, Y. P. Lee, A. M. Mebel, L. C. Lee, M. C. Liang, and Y. L. Yung, Astrophys. J. 647, 1535 (2006).

${ }^{40}$ J. A. Syage, R. B. Cohen, and J. Steadman, J. Chem. Phys. 97, 6072 (1992).

${ }^{41}$ V. Vaida, M. I. McCarthy, P. C. Engelking, and P. Botschwina, J. Chem. Phys. 86, 6669 (1987).

${ }^{42}$ Y. J. Wu, H. C. Lu, H. K. Chen, and B. M. Cheng, J. Chem. Phys. 127, 154311 (2007).

${ }^{43}$ S. R. La Paglia and A. B. F. Duncan, J. Chem. Phys. 34, 1003 (1961).

${ }^{44}$ T. Shirafuji and K. Tachibana, Appl. Surf. Sci. 79, 117 (1994).

${ }^{45}$ V. C. Papadimitriou, M. R. McGillen, E. L. Fleming, C. H. Jackman, and J. B. Burkholder, Geophys. Res. Lett. 40, 440 (2013).

${ }^{46}$ J. B. Nee, M. Suto, and L. C. Lee, J. Phys. B At. Mol. Phys. 18, L293 (1985)

${ }^{47}$ F. Carnovale, R. Tseng, and C. E. Brion, J. Phys. B At. Mol. Phys. 14, 4771 (1981).

${ }^{48} \mathrm{~K}$. P. Huber and G. Herzberg, Molecular Spectra and Molecular Structure Constants of Diatomic Molecules (van Nostrand-Reinhold, New York, 1979), Vol. IV. ${ }^{49}$ C. T. Cheah, M. A. A. Clyne, and F. D. Whitefield, J. Chem. Soc. Faraday Trans. II 76, 711 (1980).

${ }^{50}$ C. T. Cheah and M. A. A. Clyne, J. Photochem. 15, 21 (1981).

${ }^{51}$ J. J. Sloan, D. G. Watson, and J. Williamson, Chem. Phys. Lett. 74, 481 (1980).

${ }^{52}$ C. Xiao, G. Shen, X. Wang, H. Fan, and X. Yang, J. Phys. Chem. 114, 4520 (2010).

${ }^{53}$ H. J. Riedl and J. Dahmlos, U.S. patent 3,005,684 (1961). 